Trinity University

Digital Commons @ Trinity

Chemistry Faculty Research

Chemistry Department

2-18-2009

\title{
Multivalent Recognition of Peptides by Modular Self-Assembled Receptors
}

Joseph J. Reczek

Aimee A. Kennedy

Trinity University

Brian T. Halbert

Trinity University

Adam R. Urbach

TrinityUniversity, aurbach@trinity.edu

Follow this and additional works at: https://digitalcommons.trinity.edu/chem_faculty

Part of the Chemistry Commons

\section{Repository Citation}

Reczek, J. J., Kennedy, A. A., Halbert, B. T., \& Urbach, A. R. (2009). Multivalent recognition of peptides by modular self-assembled receptors. Journal of the American Chemical Society, 131(6), 2408-2415. doi: 10.1021/ja808936y

This Post-Print is brought to you for free and open access by the Chemistry Department at Digital Commons@ Trinity. It has been accepted for inclusion in Chemistry Faculty Research by an authorized administrator of Digital Commons @ Trinity. For more information, please contact jcostanz@trinity.edu. 


\title{
Multivalent Recognition of Peptides by Modular Self-
}

\section{Assembled Receptors}

\author{
Joseph J. Reczek, ${ }^{\S}$ Aimee A. Kennedy, Brian T. Halbert, and Adam R. Urbach* \\ Department of Chemistry, Trinity University, San Antonio, TX, 78212
}

Email: adam.urbach@trinity.edu

\section{RECEIVED DATE}

$\S$ Current address: Department of Chemistry and Biochemistry, Denison University, Granville, OH, 43023.

Abstract: Developing nontraditional approaches to the synthesis and characterization of multivalent compounds is critical to our efforts to study and interface with biological systems and to build new noncovalent materials. This paper demonstrates a biomimetic approach to the construction of discrete, modular, multivalent receptors via molecular self-assembly in aqueous solution. Scaffolds presenting 1-3 viologen groups recruit a respective 1-3 copies of the synthetic host, cucurbit[8]uril, in an noncooperative manner and with a consistent equilibrium association constant $\left(K_{a}\right)$ value of $2 \times 10^{6} \mathrm{M}^{-1}$ per binding site. The assembled mono-, di-, and trivalent receptors bind to their cognate target peptides containing 1-3 Trp residues with $K_{a}$ values in the range $1.7 \times 10^{4}$ to $4.7 \times 10^{6} \mathrm{M}^{-1}$ and in predetermined mono- or multivalent binding modes with 31-280-fold enhancements in affinity and additive enthalpies due to multivalency. The extent of valency was determined directly by measuring the visible chargetransfer absorptivity due to the viologen-indole pair. The predictable behavior of this system and its ease of synthesis and analysis make it well suited to serve as a model for multivalent binding and for the 
multivalent recognition of peptides by design.

\section{Introduction}

The simultaneous association of multiple ligands on one entity with multiple receptors on another"multivalent binding"-is believed to play a fundamental role in myriad biochemical processes, including signal transduction, pathogenic infection and the immune response, and is involved in the bottom-up molecular self-assembly of nanoscale architectures. ${ }^{1}$ Exploring new methods for the synthesis and characterization of multivalent compounds is therefore critical to our efforts to study and interface with biological systems and to build new materials. In recent years, substantial interest in this field has produced a wide range of synthetic multivalent compounds ${ }^{1 a, 2}$ as well as experimental methods and theoretical models to describe their behavior. ${ }^{3}$ Despite the successful development of many compounds that exhibit increased affinity and/or selectivity due to multivalency, however, little is known about how to control the cooperation of multiple binding events by design.
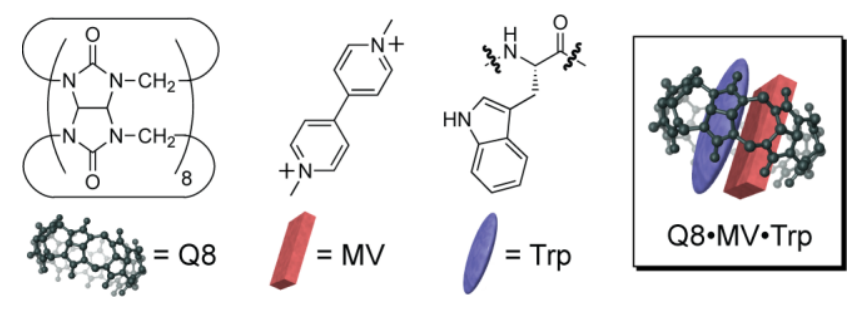

Figure 1. Structures of Q8, MV, and Trp, and a schematic of the Q8・MV•Trp complex.

Progress in this area has been slowed by difficulties inherent to synthesizing multivalent receptors and to determining the number of simultaneous interactions per complex. The principle approach to synthesizing multivalent compounds involves covalently connecting multiple copies of a ligand, ${ }^{2 \mathrm{~b}}$ or a synthetic host (e.g., cyclodextrin, vancomycin, or crown ether), ${ }^{4}$ either by direct linkage or by attachment to a common scaffold. While this approach is typically straightforward for the linkage of small ligands, the linkage of large, polar, and structurally repetitive host compounds is exceedingly slow and costly, especially for iterative structure-activity studies. Moreover, standard equilibrium binding 
assays are based on comparing the relative quantities of bound and unbound states but do not readily reveal the extent of valency (i.e., the number of simultaneous associations) in the bound state..$^{5}$ This paper describes a multivalent system, based on cucurbit[8]uril (Q8, Figure 1), that overcomes these issues of synthesis and analysis.

Q8 is a member of the cucurbit[n]uril (Qn) family of synthetic macrocyclic hosts, ${ }^{6}$ which have gained enormous interest in recent years due to their ability to bind tightly and selectively to a wide range of cationic organic compounds in aqueous solution. ${ }^{7}$ The methylene-bridged glycoluril units of a Qn molecule surround its hydrophobic cavity and present ureido carbonyl oxygens at the two constricted entrances (or portals) to this cavity. These structural features promote binding through a combination of hydrophobic inclusion of the guest and alignment of its cationic group(s) with the oxygen atoms of the Qn. While Q5, Q6, and Q7 typically bind one equivalent of organic guest, multiple guests can be accommodated simultaneously by Q8, ${ }^{6,}, 8$ Q10, ${ }^{9}$ and nor-seco-Q10. ${ }^{10} \mathrm{Q} 8$ binds to one equivalent of methyl viologen (MV) with an equilibrium association constant $\left(\mathrm{K}_{\mathrm{a}}\right)$ value of $10^{5}-10^{6} \mathrm{M}^{-}$ 1 , ${ }^{\mathrm{a}, 11}$ and the resulting Q8•MV complex can then bind efficiently to electron-rich aromatic guests such as dopamine or tryptophan (Trp). ${ }^{12}$ We have previously reported the binding of Q8•MV to Trpcontaining peptides with $\mathrm{K}_{\mathrm{a}}$ values in the range $10^{3}-10^{5} \mathrm{M}^{-1}$, depending on the peptide sequence. ${ }^{11}$ Moreover, the binding of $\operatorname{Trp}$ to $\mathrm{Q} 8 \bullet \mathrm{MV}$ is accompanied by the quantitative formation of a new visible absorbance (hence, optical sensing) due to a charge-transfer complex between the indole and viologen groups. ${ }^{11,12 \mathrm{~b}}$ The interesting properties of the Q8・MV•Trp system led us to consider a biomimetic approach to making model multivalent receptors.

Living systems use hierarchical organization to efficiently accomplish a broad diversity of function. At each level of hierarchy, the components carry out functions intrinsic to that level and also have the ability to work together to achieve higher-level functions. For example, proteins such as cell-surface receptors or viral capsid proteins can bind their targets in a monovalent fashion and also have the ability to assemble noncovalently into multivalent structures with increased affinity and/or selectivity of 
binding, or with new function such as pore formation or encapsulation. ${ }^{\text {a, d }}$ Here we show how Q8 can mimic these proteins via its unique ability to bind selectively to two different guests: 1) a target peptide; and 2) a viologen that can be used to direct its noncovalent assembly with other Q8 molecules. In the scheme shown in Figure 2, two molecules of Q8 assemble onto a scaffold presenting two viologen groups. The resulting self-assembled receptor then binds in a discrete divalent fashion to a peptide with two tryptophan residues.

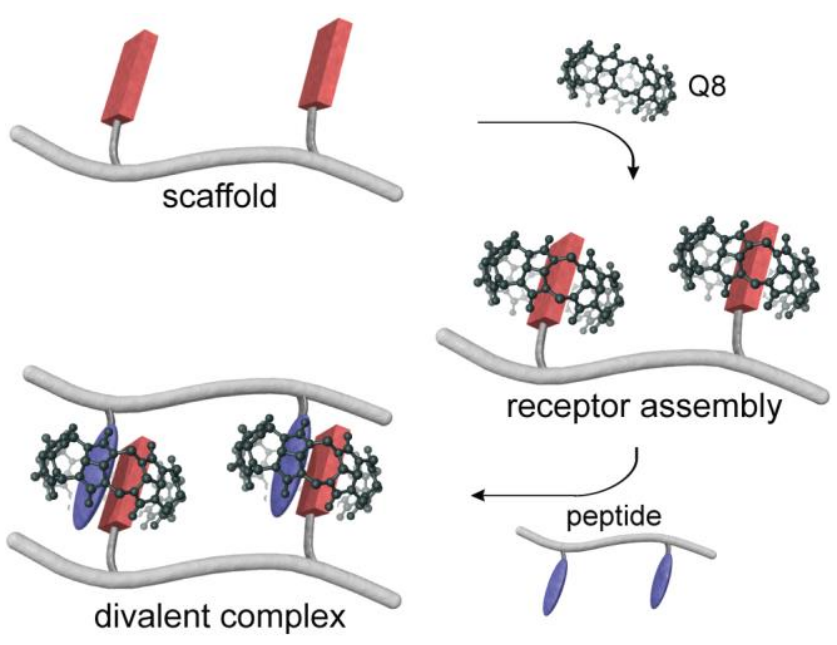

Figure 2. Schematic illustration of the concept of a self-assembling modular receptor. A divalent scaffold presenting viologen groups (in red) recruits two equivalents of Q8, and the resulting receptor binds in a divalent fashion to a peptide with two tryptophan groups (in blue).

Peptide-based scaffolds functionalized with one, two, or three $(n)$ viologen groups were prepared by solid phase methods. Isothermal titration calorimetry was used to determine the thermodynamic parameters for the binding of these compounds to $n$ equivalents of Q8 (i.e., receptor assembly), and for the binding of the resulting self-assembled receptors to peptides containing $n \operatorname{Trp}$ residues, respectively. We find that all receptors assemble in a noncooperative manner and then bind to their cognate peptide targets in predetermined mono- or multivalent modes with 31 - to 280 -fold increases in affinity due to multivalency, all in aqueous solution at $\mathrm{pH}$ 7. The built-in optical sensor, based on the Trp-MV chargetransfer complex, allows for direct quantitation of the extent of valency in each complex using UVvisible spectroscopy. To the best of our knowledge, this is the first time it has been possible to direct the noncovalent assembly of multiple synthetic hosts into discrete multivalent constructs while still 
maintaining the capacity for the hosts to bind to a target guest. Moreover, the predictable behavior of this system and its ease of synthesis and analysis make it well suited to serve as a model for multivalent binding and for the multivalent recognition of peptides by designed molecules. ${ }^{13}$

\section{Results}

Synthesis. Compounds 1-6 (Figure 3) ${ }^{14}$ were synthesized on solid-support by standard fmoc protocols, purified by reversed phase HPLC, and characterized by ${ }^{1} \mathrm{H}$ NMR, analytical HPLC, and mass spectrometry. For compounds 1-3 we developed a new synthetic strategy for linking viologen groups to a peptide on solid support. Briefly, dimethylbenzyl-protected glutamic acid (Glu) residues were installed at positions where viologen groups were to be coupled. After acetylation of the N-terminal amine, the Glu residues were deprotected in dilute acid, then activated with pentafluorophenol and diisopropylcarbodiimide and coupled in situ to an aminoethyl derivative of methyl viologen (see Supporting Information for details). 

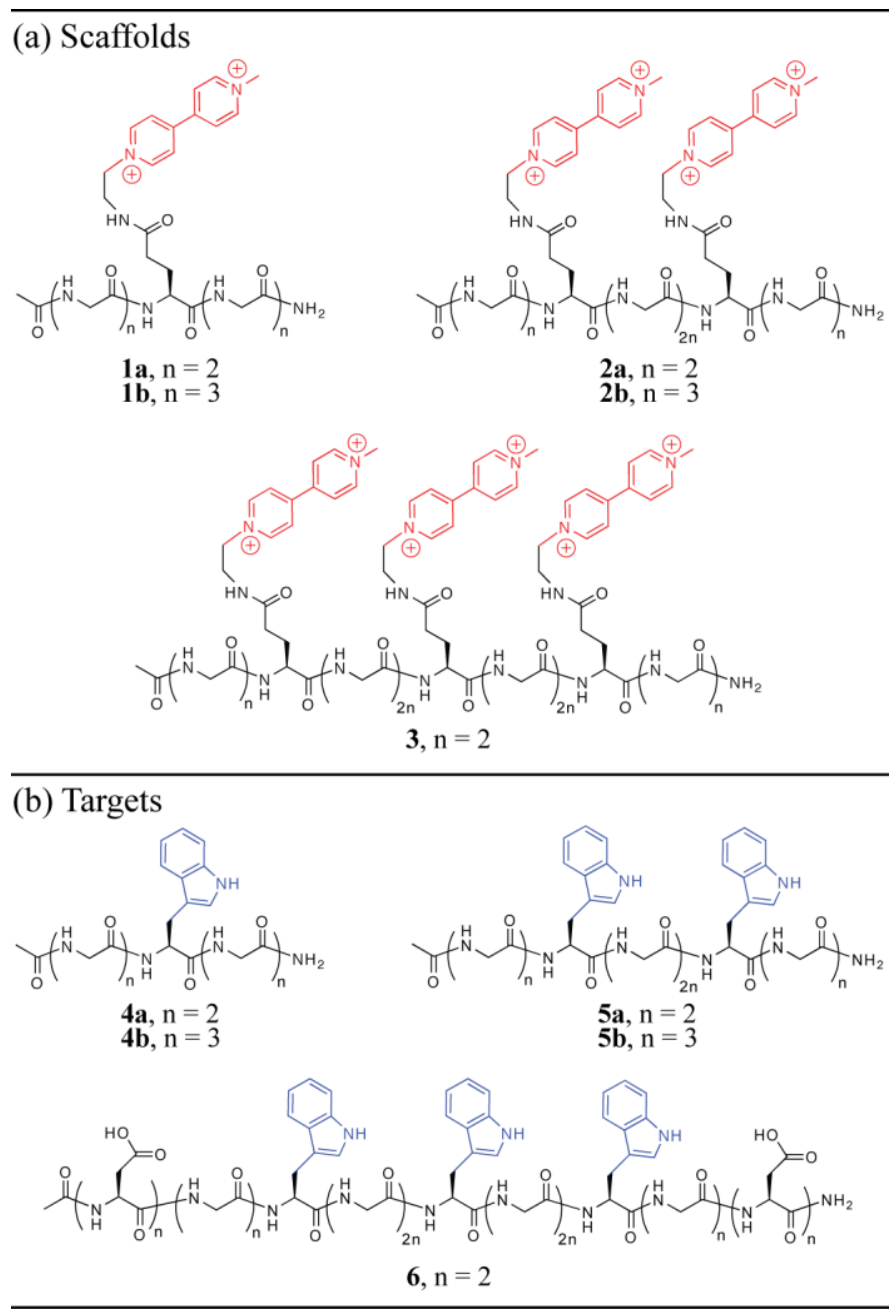

Figure 3. Chemical structures of compounds 1-6.

Equilibrium Binding Studies. The binding of Q8 to compounds 1-3 was measured by ITC to determine the stoichiometry and affinity of complexation. ${ }^{15}$ The data in Table 1 show that scaffold compounds 1, 2, and $\mathbf{3}$ bind to one, two, and three molar equivalents of $\mathrm{Q} 8$ to form receptor complexes $1 \cdot \mathrm{Q} 8, \mathbf{2} \cdot \mathrm{Q} 8$, and $3 \cdot \mathrm{Q} 83$, respectively. $\mathrm{K}_{\mathrm{a}}$ values were virtually identical for all scaffolds tested. The presence of all complexes was confirmed by electrospray mass spectrometry (ESI-MS).

Table 1. Binding of Scaffolds to Q8.

Scaffold $\mathrm{K}_{\mathrm{a}}\left(\mathrm{M}^{-1}\right)^{\mathrm{a}}$




\begin{tabular}{cl}
\hline $\mathbf{1 a}$ & $2.1( \pm 0.1) \times 10^{6}$ \\
$\mathbf{1 b}$ & $2.0( \pm 0.1) \times 10^{6}$ \\
$\mathbf{2 a}$ & $2.2( \pm 0.3) \times 10^{6}$ \\
$\mathbf{2 b}$ & $2.1( \pm 0.2) \times 10^{6}$ \\
$\mathbf{3}$ & $1.6( \pm 0.1) \times 10^{6}$
\end{tabular}

a Data were fit to a one set of sites model in Origin 7.0 software. Standard deviations are given in parentheses. Values were determined from at least three ITC experiments in $10 \mathrm{mM}$ sodium phosphate, $\mathrm{pH} 7.0$, at $27^{\circ} \mathrm{C}$.

Receptors were preassembled by mixing viologen-containing compounds, $\mathbf{1}, \mathbf{2}$, and $\mathbf{3}$, with one, two, and three molar equivalents of $\mathrm{Q} 8$, respectively. Binding of the resulting receptor complexes, $\mathbf{1} \cdot \mathrm{Q} 8$, $\mathbf{2} \cdot \mathrm{Q}_{2}$, and $\mathbf{3} \cdot \mathrm{Q} 8_{3}$, to target peptides 4-6 was measured by ITC to determine the stoichiometry and thermodynamic parameters of complexation (Table 2). The divalent and trivalent receptor complexes were kept in the sample cell of the calorimeter at concentrations at or above $20 \mu \mathrm{M}$ to ensure that the majority of Q8 was bound to viologen during the experiment. Monovalent, divalent, and trivalent receptors, $\mathbf{1} \cdot \mathrm{Q} 8, \mathbf{2} \cdot \mathrm{Q} 82$, and $\mathbf{3} \cdot \mathrm{Q} 8_{3}$, bound to one, two, and three molar equivalents, respectively, of monovalent target peptides, 4 (i.e., $\mathbf{4 a}$ and $\mathbf{4 b}$ ). Each divalent receptor, $\mathbf{2} \cdot \mathrm{Q} 8$, bound to one equivalent of divalent peptides, $\mathbf{5}$, and the trivalent receptor, $\mathbf{3} \cdot \mathrm{Q} 8_{3}$, bound to one equivalent of trivalent peptide, 6. ${ }^{16}$ The presence of all complexes was confirmed by ESI-MS.

Average $\mathrm{K}_{\mathrm{a}}$ values were consistently $2 \times 10^{4} \mathrm{M}^{-1}$ for complexation with monovalent peptides, 4. The increase in binding affinity due to multivalency was an average 31 -fold for divalent complexes, $\mathbf{2} \cdot \mathrm{Q}_{2} \cdot \mathbf{5}$, and 280 -fold for the trivalent complex, $\mathbf{3} \cdot \mathrm{Q}_{3} \cdot \mathbf{6}$. In all cases, binding was exothermic $(\Delta \mathrm{H}<$ 0 ), enthalpically driven $(|\Delta \mathrm{H}|>|\mathrm{T} \Delta \mathrm{S}|)$, and entropically unfavorable $(-\mathrm{T} \Delta \mathrm{S}>0)$. The magnitude of enthalpy and entropy increased with the valency of the target peptide. Divalent complexes had approximately twice the enthalpy of the monovalent complexes (average $\Delta \Delta \mathrm{H}=-11.7 \mathrm{kcal} / \mathrm{mol}$ ), but more than twice the entropy (average $-\mathrm{T} \Delta \Delta \mathrm{S}=9.7 \mathrm{kcal} / \mathrm{mol}$ ), resulting in the 31 -fold increase in affinity. The trivalent complex had approximately three times the enthalpy of the monovalent 
complexes $(\Delta \Delta \mathrm{H}=-26.9 \mathrm{kcal} / \mathrm{mol})$, but substantially more than three times the entropy $(-\mathrm{T} \Delta \Delta \mathrm{S}=23.5$

$\mathrm{kcal} / \mathrm{mol}$ ), resulting in the 280 -fold increase in affinity.

Table 2. Thermodynamic Data for Binding of Assembled Receptors to Target Peptides.

\begin{tabular}{|c|c|c|c|c|c|c|}
\hline Receptor & Target & $\mathrm{n}^{\mathrm{a}}$ & $\begin{array}{c}\mathrm{K}_{\mathrm{a}}^{\mathrm{b}} \\
\left(\mathrm{M}^{-1}\right)\end{array}$ & $\begin{array}{c}\Delta \mathrm{G}^{\mathrm{c}} \\
(\mathrm{kcal} / \mathrm{mol})\end{array}$ & $\begin{array}{c}\Delta \mathrm{H}^{\mathrm{b}} \\
(\mathrm{kcal} / \mathrm{mol})\end{array}$ & $\begin{array}{c}-\mathrm{T} \Delta \mathrm{S}^{\mathrm{d}} \\
(\mathrm{kcal} / \mathrm{mol})\end{array}$ \\
\hline $\mathbf{1 a} \cdot \mathrm{Q} 8$ & $4 a$ & 1.02 & $2.2( \pm 0.1) \times 10^{4}$ & $-5.9( \pm 0.1)$ & $-10.8( \pm 0.1)$ & $4.9( \pm 0.1)$ \\
\hline $\mathbf{1 a} \cdot \mathrm{Q} 8$ & $4 b$ & 1.06 & $2.2( \pm 0.1) \times 10^{4}$ & $-6.0( \pm 0.1)$ & $-11.0( \pm 0.1)$ & $5.0( \pm 0.1)$ \\
\hline $\mathbf{1 b} \cdot \mathrm{Q} 8$ & $4 a$ & 1.03 & $1.9( \pm 0.1) \times 10^{4}$ & $-5.9( \pm 0.1)$ & $-10.8( \pm 0.2)$ & $4.9( \pm 0.2)$ \\
\hline $\mathbf{1 b} \cdot \mathrm{Q} 8$ & $4 b$ & 1.03 & $2.2( \pm 0.1) \times 10^{4}$ & $-6.0( \pm 0.1)$ & $-11.0( \pm 0.1)$ & $4.9( \pm 0.1)$ \\
\hline $\mathbf{2 a} \cdot \mathrm{Q}_{2}$ & $4 a$ & 2.07 & $1.7( \pm 0.1) \times 10^{4}$ & $-5.8( \pm 0.1)$ & $-12.8( \pm 0.2)$ & $7.0( \pm 0.2)$ \\
\hline $\mathbf{2 a} \cdot Q 8 \mathbf{2}$ & $4 b$ & 2.07 & $1.5( \pm 0.1) \times 10^{4}$ & $-5.8( \pm 0.1)$ & $-13.0( \pm 0.3)$ & $7.2( \pm 0.4)$ \\
\hline $\mathbf{2 b} \cdot \mathrm{Q} 82$ & $4 a$ & 1.95 & $1.8( \pm 0.2) \times 10^{4}$ & $-5.8( \pm 0.1)$ & $-11.8( \pm 0.1)$ & $5.9( \pm 0.1)$ \\
\hline $\mathbf{2 b} \cdot \mathrm{Q} 8 \mathbf{2}$ & $4 b$ & 1.94 & $1.4( \pm 0.1) \times 10^{4}$ & $-5.7( \pm 0.1)$ & $-12.3( \pm 0.1)$ & $6.6( \pm 0.1)$ \\
\hline $\mathbf{2 a} \cdot \mathrm{Q} 82$ & $5 \mathbf{a}$ & 1.05 & $5.0( \pm 0.1) \times 10^{5}$ & $-7.8( \pm 0.1)$ & $-24.2( \pm 0.1)$ & $16.3( \pm 0.1)$ \\
\hline $\mathbf{2} \mathbf{a} \cdot \mathrm{Q}^{2} \mathbf{2}$ & $5 \mathbf{b}$ & 1.07 & $4.6( \pm 0.1) \times 10^{5}$ & $-7.8( \pm 0.1)$ & $-24.8( \pm 0.4)$ & $17.1( \pm 0.4)$ \\
\hline $\mathbf{2 b} \cdot \mathrm{Q}_{2}$ & $5 \mathbf{a}$ & 1.04 & $5.5( \pm 0.1) \times 10^{5}$ & $-7.9( \pm 0.1)$ & $-23.4( \pm 0.1)$ & $15.6( \pm 0.1)$ \\
\hline $\mathbf{2 b} \cdot \mathrm{Q}_{2}$ & $5 \mathbf{b}$ & 1.01 & $5.0( \pm 0.1) \times 10^{5}$ & $-7.8( \pm 0.1)$ & $-24.3( \pm 0.2)$ & $16.5( \pm 0.2)$ \\
\hline $3 \cdot \mathrm{Q}_{3}$ & $4 a$ & 2.97 & $1.7( \pm 0.1) \times 10^{4}$ & $-5.8( \pm 0.1)$ & $-12.2( \pm 0.1)$ & $6.4( \pm 0.2)$ \\
\hline $3 \cdot \mathrm{Q}_{3}$ & 6 & 1.01 & $4.7( \pm 0.8) \times 10^{6 \mathrm{e}}$ & $-9.2( \pm 0.1)^{\mathrm{e}}$ & $-39.4( \pm 1.4)^{\mathrm{e}}$ & $30.2( \pm 1.5)^{\mathrm{e}}$ \\
\hline
\end{tabular}

a Observed molar ratio of target:receptor. Standard deviations are less than $4 \%$. ${ }^{\mathrm{b}}$ Mean values measured from at least three ITC experiments at $27^{\circ} \mathrm{C}$ in $10 \mathrm{mM}$ sodium phosphate, $\mathrm{pH}$ 7.0. Standard deviations are given in parentheses. ${ }^{c}$ Gibbs free energy values calculated from $\mathrm{K}_{\mathrm{a}}$ values. Standard deviations for $\Delta \mathrm{G}$ values were calculated as the relative error observed in $\mathrm{K}_{\mathrm{a}}$, due to their relationship by a natural logarithm. ${ }^{\mathrm{d}}$ Entropic contributions to $\Delta \mathrm{G}$ calculated from $\mathrm{K}_{\mathrm{a}}$ and $\Delta \mathrm{H}$ values, with error propagated from that of $\mathrm{K}_{\mathrm{a}}$ and $\Delta \mathrm{H}$. ${ }^{\mathrm{e}}$ Data for the $\mathbf{3} \cdot \mathrm{Q} \mathbf{3}_{3} \cdot \mathbf{6}$ complex were determined as described in footnote 16.

UV-Visible Spectroscopy. Figure 4 shows an overlay of UV-visible spectra for complexes $\mathbf{1 a} \cdot \mathrm{Q} 8 \cdot \mathbf{4 a}, \mathbf{2} \mathbf{a} \cdot \mathrm{Q} 8{ }_{2} \cdot \mathbf{5 a}$, and $\mathbf{3} \cdot \mathrm{Q} 8{ }_{3} \cdot \mathbf{6}$, plotted as molar absorptivities. ${ }^{17}$ The average charge-transfer 
absorptivity at $480 \mathrm{~nm}\left(\varepsilon_{480}\right)$ for all $\mathbf{2} \cdot \mathrm{Q}_{2} \cdot \mathbf{5}$ complexes $\left(795 \pm 9 \mathrm{M}^{-1} \mathrm{~cm}^{-1}\right)$ was twice that for all $\mathbf{1} \cdot \mathrm{Q} 8 \bullet \mathbf{4}$ complexes $\left(391 \pm 8 \mathrm{M}^{-1} \mathrm{~cm}^{-1}\right)$, and the $\varepsilon_{480}$ for $\mathbf{3} \cdot \mathrm{Q} 8_{3} \cdot \mathbf{6}\left(1193 \mathrm{M}^{-1} \mathrm{~cm}^{-1}\right)$ was three times the average $\varepsilon_{480}$ for all $1 \cdot \mathrm{Q} 8 \cdot 4$ complexes.

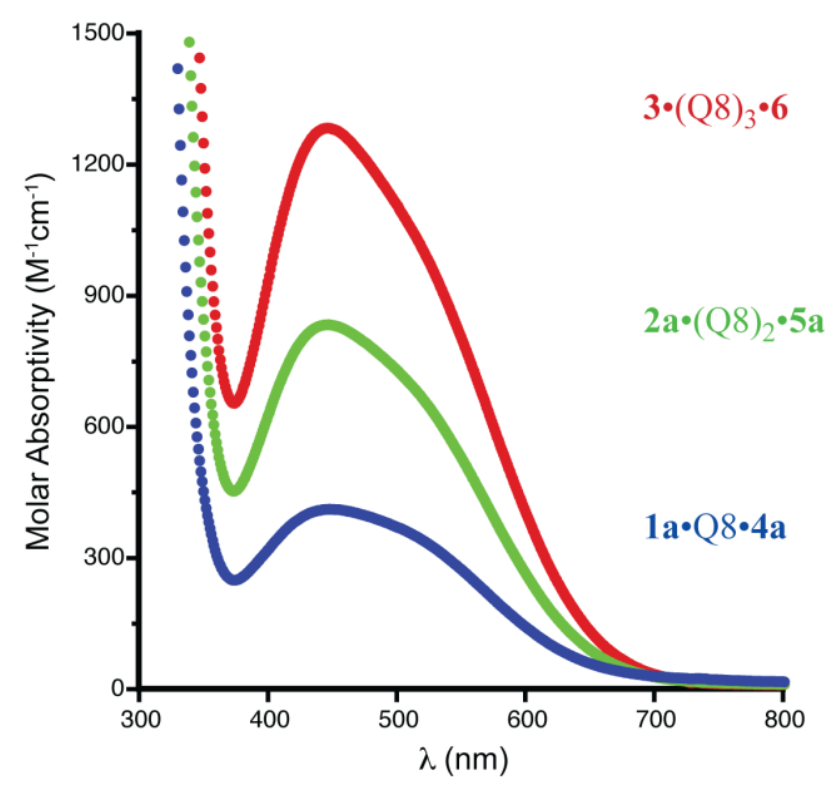

Figure 4. UV-visible spectra of representative monovalent $(\mathbf{1} \cdot \cdot \mathbf{Q} 8 \cdot \mathbf{4 a})$, divalent $\left(\mathbf{2 a} \cdot \mathrm{Q}_{2} \cdot \mathbf{5 a}\right)$, and trivalent complexes $\left(\mathbf{3} \cdot \mathrm{Q} \mathbf{8}_{3} \cdot \mathbf{6}\right)$, plotted in molar absorptivity.

\section{Discussion}

Design Considerations. Compounds 1-6 (Figure 3) have the principle advantage of being easy to synthesize and modify. In designing this series, we addressed several important issues: 1) The linkage between binding sites can participate in binding and must therefore be controlled if one wants to obtain a meaningful comparison between monovalent and higher valency complexes. We addressed this issue by designing the compounds in a truly modular fashion, where divalent and trivalent compounds are two-fold and three-fold repeats of their monovalent analogues, including the peptide backbone. 2) To help ensure that multiple binding sites on a single compound can interact simultaneously with their targets, we designed the linkage between binding sites to be conformationally flexible and of sufficient length to accommodate multiple Q8 molecules. A logical starting point was to make the Trp-containing 
target peptides, 4-6, ${ }^{14}$ sequentially analogous to the viologen-containing scaffold compounds, $\mathbf{1 - 3}$, using flexible Gly residues for the linkage. We found that an exact trivalent analogue of $\mathbf{4 a}$ has a solubility limit of $\sim 1 \mu \mathrm{M}$, which precludes analysis by ITC (while keeping viologen $\bullet \mathrm{Q} 8$ complexes saturated). An analogue with two additional Asp residues at each terminus was prepared. The resulting compound $\mathbf{6}$ is soluble in excess of $200 \mu \mathrm{M}$. Prior work on the binding of Q8•MV to tryptophan derivatives and Trpcontaining peptides suggests that the negative charges will have negligible effect on binding. 3) All structures must be designed to minimize unintended adhesion of Q8 to sufficiently hydrophobic and/or electropositive sites. We addressed this concern by placing positive charges on only the viologen groups and by keeping alkyl chains to a length of three or fewer carbons. ${ }^{18}$ N-termini were acetylated, and C-termini were primary amides in order to reduce the effects of electrostatic charge at these positions. $^{11}$

Self-Assembly of Receptors. All scaffolds, 1-3, bound to Q8 with $\mathrm{K}_{\mathrm{a}}$ values of 2 x $10^{6} \mathrm{M}^{-1}$ per binding site. ${ }^{15}$ The similarity of these binding constants to each other and to those observed previously for the binding of Q8 to methyl viologen $\left(\mathrm{K}_{\mathrm{a}}=8.5 \times 10^{5} \mathrm{M}^{-1}\right)$ supports a similar mode of binding among these complexes, demonstrates that linking viologen groups to these scaffolds does not diminish their ability to bind to Q8, and exemplifies the non-cooperativity of this process. The small increase in the binding affinity to Q8 for scaffolds 1-3 relative to methyl viologen may be due to additional dipoledipole interactions between Q8 and the amide $\mathrm{NH}$ groups on the linker and/or scaffold, as observed in previous structural studies of Q8•peptide complexes. ${ }^{19}$ The ability of scaffolds $\mathbf{2}$ and $\mathbf{3}$ to bind two and three equivalents of $\mathrm{Q} 8$, respectively, with no change in binding affinity shows that the multivalent scaffolds are able to accommodate the steric demands of multiple Q8 molecules without an energetic penalty.

Monovalent Peptide Targets. Receptor complexes, $\mathbf{1} \bullet \mathrm{Q} 8, \mathbf{2} \cdot \mathrm{Q} 82$, and $\mathbf{3} \bullet \mathrm{Q} 8$, bound to monovalent 
target peptides, 4, with $\mathrm{K}_{\mathrm{a}}$ values of approximately $2 \times 10^{4} \mathrm{M}^{-1}$ per binding site. ${ }^{15}$ The consistency among these values and that observed previously for Q8 $\bullet$ MV binding to Gly-Gly-Trp-Gly-Gly $\left(\mathrm{K}_{\mathrm{a}}=2.5\right.$ x $\left.10^{4} \mathrm{M}^{-1}\right)^{11}$ supports a similar mode of binding among these complexes, shows that linkage of viologen $\cdot \mathrm{Q} 8$ complexes to these scaffolds does not adversely affect their ability to bind to Trpcontaining peptides, and exemplifies the noncooperativity of this process. Moreover, the binding of multivalent receptor complexes, $2 \cdot \mathrm{Q} 8_{2}$ and $\mathbf{3} \cdot \mathrm{Q} 8_{3}$, to two and three equivalents, respectively, of monovalent peptide shows that the multivalent receptors are able to simultaneously accommodate the steric demands of multiple monovalent target molecules with no energetic penalty. The consistency and predictability observed for the binding of Q8 and, subsequently, of monovalent peptide establishes an essential baseline for their comparison to multivalent analogues.

Divalent Peptide Targets: Mode of Binding. In studying the binding of divalent receptors, $\mathbf{2} \bullet \mathrm{Q} 8_{2}$, to their analogous multivalent target peptides, $\mathbf{5}$, we first needed to provide evidence for the mode of binding. Specifically, we were concerned about the formation of supramolecular oligomers instead of, or in addition to, the desired discrete multivalent complexes (Figure 5). To assign the mode of binding, we present the following case.

Our system has the characteristic that simultaneous inclusion of viologen and indole groups in the cavity of Q8 produces a quantitative increase in visible absorbance, which is due to the formation of a charge-transfer complex between the two aromatic groups. ${ }^{11,12 b}$ Therefore, the molar absorptivity due to this charge-transfer complex is related directly to the number of simultaneous binding events per molecule. The UV-visible spectral data (Figure 4) show that the charge-transfer absorptivities of the divalent and trivalent complexes are two-fold and three-fold greater, respectively, than those of the monovalent complexes. This result shows that $>95 \%$ of the possible Q8•viologen tryptophan complexes are simultaneously formed, and would be true only for discrete multivalent complexes as well as for long (>20-mer) supramolecular oligomers. 

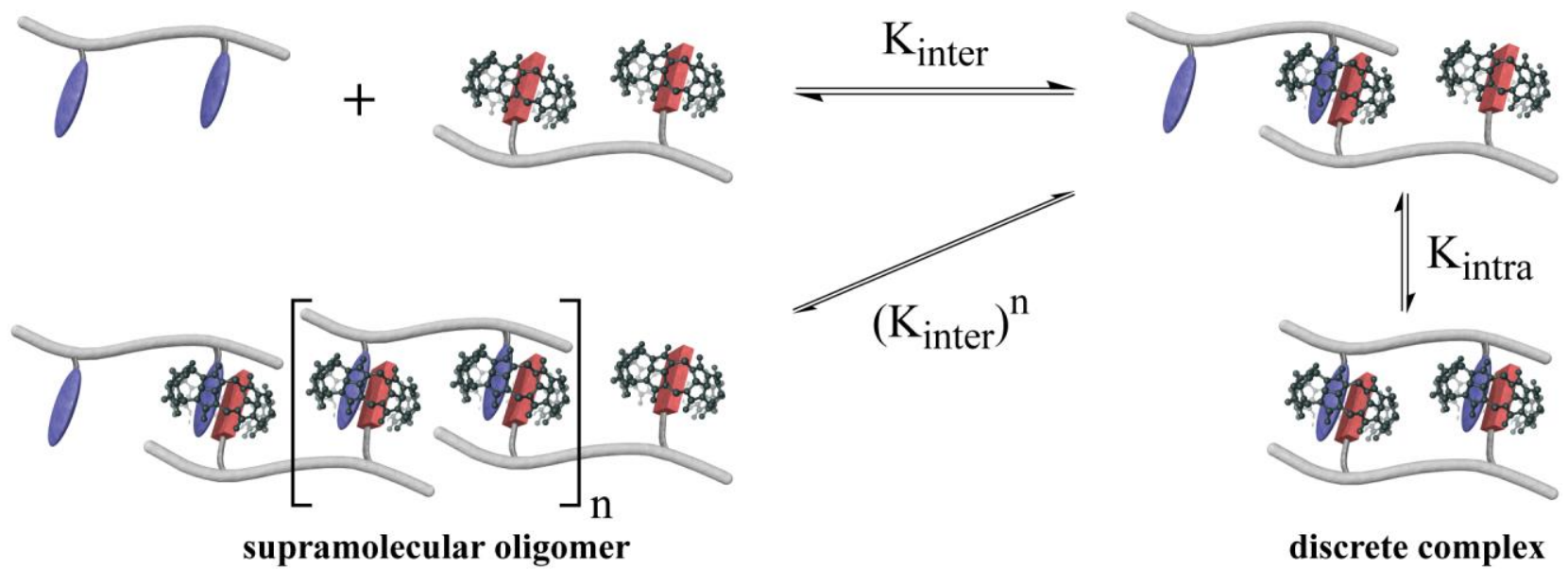

discrete complex

Figure 5. Schematic illustration of the stepwise binding of a divalent receptor with a divalent target peptide. In the first step, intermolecular association $\left(K_{\text {inter }}\right)$ yields a complex which can either close intramolecularly $\left(K_{\text {intra }}\right)$ into a discrete complex or associate intermolecularly with additional divalent compounds $\left(K_{\text {inter }}{ }^{n}\right)$ into a supramolecular oligomer.

ITC data for the formation of divalent $\left(\mathbf{2} \cdot \mathrm{Q} 8_{2} \cdot \mathbf{5}\right)$ complexes show a single-phase isotherm (Figure 6), which fits well to a one-set-of-sites binding model and which has an inflection point at a 1:1 molar ratio of target:receptor. Considering the argument presented in the following paragraph, this result suggests that only one type of binding mode is occurring throughout the titration: 1) each molecule of target peptide binds once to a receptor molecule; or 2) each molecule of target binds multiple times to a receptor molecule. The UV-visible spectra discussed in the previous paragraph effectively rule out option 1. Moreover, the observed binding enthalpies for the formation of $\mathbf{2} \cdot \mathrm{Q} 8_{2} \cdot \mathbf{5}$ complexes are approximately two-fold greater than those for the formation of $\mathbf{1} \bullet \mathrm{Q} 8 \bullet \mathbf{4}$, as expected for the binding of two identical sites connected by a flexible linker. ${ }^{1 \mathrm{a}}$ The combination of these results and the fact that oligomeric species were not observed by mass spectrometry leads us to conclude that these complexes form in a discrete, multivalent fashion. 


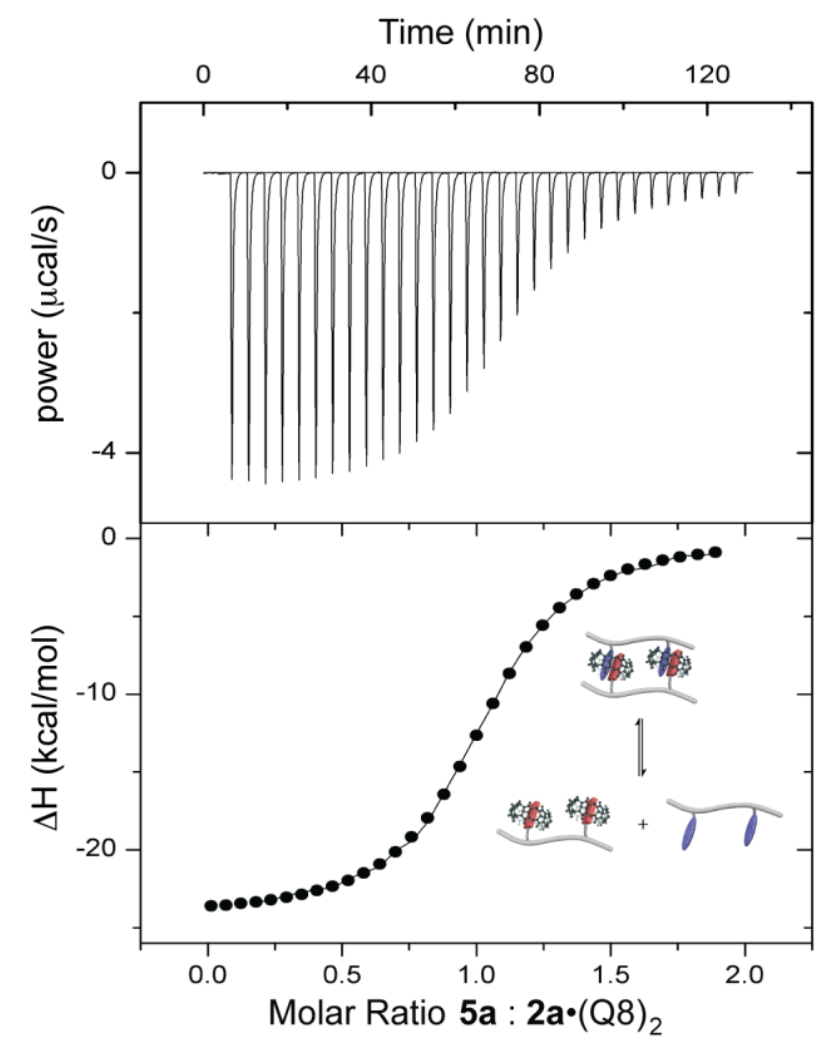

Figure 6. ITC data for the binding of divalent target peptide 5 a to divalent receptor assembly $2 \mathrm{a} \cdot \mathrm{Q} 8_{2}$ at $27^{\circ} \mathrm{C}$ in $10 \mathrm{mM}$ sodium phosphate buffer, pH 7.0. 5a was titrated at $0.60 \mathrm{mM}$ into a $0.065 \mathrm{mM}$ sample of $\mathbf{2 a} \cdot \mathbf{Q} 8_{2}$. The top plot shows the raw data for power applied as a function of time. The integrated enthalpy values are plotted at the bottom as a function of the molar ratio of $5 \mathrm{a}: 2 \mathrm{a} \cdot \mathrm{Q} 8_{2}$.

Supramolecular oligomerization can be ruled out on the basis of the ITC data by considering the following argument. Early in the titration of a divalent target peptide into a solution of divalent receptor, there is a vast excess of available receptor. If oligomerization were favored, then each molecule of target would bind to two equivalents of receptor such that both tryptophan residues were occupied. The Caruthers equation (Eq. 1) predicts the number average degree of polymerization, $X_{n}$, on

$$
X_{n},=1 /(1-p)
$$

Eq. 1

the basis of extent of reaction, $p$. We determined $p$ values from the equilibrium constants reported in Table 2 and the experimental concentrations. This equation predicts an average length of two units at a target:receptor ratio of $1: 2$, three units at a ratio of $3: 4$, and six units at the equivalence point. Over this portion of the titration, newly titrated target molecules could bind to two free receptors or could link a free receptor to a growing oligomer; in both cases, the measured enthalpy would reflect the binding of both Trp residues per molecule of titrant. Near and after the equivalence point, however, the probability 
of newly titrated target molecules to bind to multiple free receptor sites becomes very low. Therefore, the titration experiment should show at least two phases: 1) before the equivalence point, a phase which reflects the enthalpy of binding for two Trp residues per titrated target molecule; and 2) after the equivalence point, a phase which reflects the enthalpy of binding of one Trp residue per titrated target molecule. Our observation of a single-phase isotherm is inconsistent with this model, and thus we rule out the formation of oligomers.

Divalent Peptide Targets: Effects of the Distance Between Binding Sites. In order to assess whether the distance between binding sites influences the formation of divalent complexes, we varied the oligo(Gly) linker between viologen groups in divalent scaffolds, 2, and between tryptophan residues in divalent targets, 5 , between four ( $2 \mathrm{a}$ and $5 \mathrm{a})$ and six $(2 \mathrm{~b}$ and $5 \mathrm{~b})$ Gly units. As seen from the data in Table 2, no significant difference was observed. Similarly there was no significant difference observed for the analogous monovalent derivatives, 1a, 1b, 4a, and $4 \mathbf{b}$. These results are not surprising given the expectation that oligo(Gly) linkers would have little conformational preference.

The similarities observed here allow us to simplify subsequent analysis of the thermodynamic data by averaging the values all four combinations of scaffold and target for each type of complex (Table 3 ). For example, data for the formation of $\mathbf{1 a} \cdot \mathrm{Q} 8 \cdot \mathbf{4 a}, \mathbf{1 b} \cdot \mathrm{Q} 8 \cdot \mathbf{4 a}, \mathbf{1 b} \cdot \mathrm{Q} 8 \cdot \mathbf{4 a}$, and $\mathbf{1 b} \cdot \mathrm{Q} 8 \cdot \mathbf{4} \mathbf{b}$ is shown simply as $1 \cdot \mathrm{Q} 8 \cdot 4$, with an uncertainty determined by propagating the error in each experiment through the calculation of an average.

Table 3. Average thermodynamic constants for Gly 4 vs. Gly 6 linkers. ${ }^{a}$

\begin{tabular}{ccccc}
\hline \multirow{2}{*}{ Receptor } & $\mathrm{K}_{\mathrm{a}}$ & $\Delta \mathrm{G}$ & $\Delta \mathrm{H}$ & $-\mathrm{T} \Delta \mathrm{S}$ \\
& $\left(\mathrm{M}^{-1}\right)$ & $(\mathrm{kcal} / \mathrm{mol})$ & $(\mathrm{kcal} / \mathrm{mol})$ & $(\mathrm{kcal} / \mathrm{mol})$ \\
\hline
\end{tabular}




\begin{tabular}{llllr}
\hline $\mathbf{1} \cdot \mathrm{Q} 8 \bullet 4$ & $2.1( \pm 0.1) \times 10^{4}$ & $-6.0( \pm 0.1)$ & $-10.9( \pm 0.1)$ & $4.9( \pm 0.1)$ \\
$\mathbf{2} \cdot \mathrm{Q} 8_{2} \bullet \mathbf{4}_{2}$ & $1.6( \pm 0.1) \times 10^{4}$ & $-5.8( \pm 0.1)$ & $-12.5( \pm 0.3)$ & $6.7( \pm 0.3)$ \\
$\mathbf{2} \cdot \mathrm{Q} 8{ }_{2} \bullet \mathbf{5}$ & $5.0( \pm 0.2) \times 10^{5}$ & $-7.8( \pm 0.1)$ & $-24.2( \pm 0.3)$ & $16.4( \pm 0.4)$
\end{tabular}

${ }^{\mathrm{a}}$ All values are averages of the constants reported in Table 2 for all four combinations of Gly 4 and Gly6 linkages. Errors were calculated by propagating the uncertainties reported in Table 2 through the calculation of an average.

Divalent Peptide Targets: Thermodynamic Considerations. Table 3 allows us to conveniently compare binding data for monovalent and divalent complexes. We observe an increase in $\mathrm{K}_{\mathrm{a}}$ of 31 -fold due to the second binding event. This increase is a significant improvement over monovalent binding, but an ideal system could theoretically yield an increase on the order of $10^{4}$-fold. ${ }^{1 \mathrm{a}}$ The observed trend in $\mathrm{K}_{\mathrm{a}}$ values results from an approximate doubling of the binding enthalpies but at a substantial cost in entropy. The additive enthalpy suggests that (i) both Trp residues are able to simultaneously associate with their binding sites without steric penalty, and (ii) entropy is entirely to blame for the negative cooperativity observed here.

In order to properly analyze the effects of divalent versus monovalent binding, we include a treatment of symmetry factors, as outlined by Ercolani, ${ }^{3 \mathrm{f}}$ and dissect this process into the constituent inter- and intramolecular binding events. In the formation of the $2+2$ complex, $\mathbf{2} \cdot \mathrm{Q}_{2} \cdot \mathbf{5}$, binding of the first Trp residue is designated as $K_{\text {inter, }}$, and binding of the second as $K_{\text {intra }}$ (Figure 5). A $K_{\text {inter }}$ value of $5.5 \times 10^{3} \mathrm{M}^{-1}$ is derived from the observed equilibrium constant $\left(K_{o b s(1+1)} \text {, Eq. } 2\right)^{20}$ for the formation of the

$$
K_{o b s(1+1)}=4 K_{\text {inter }}
$$

monovalent complex, $\mathbf{1} \bullet \mathrm{Q} 8 \bullet \mathbf{4}$. The observed equilibrium constant for the formation of $\mathbf{2} \bullet \mathrm{Q} 82 \cdot \mathbf{5}, K_{o b s(2+2)}$ (Eq. 3), is expressed in terms of $K_{\text {inter }}$ and $K_{\text {intra }}$, where $\sigma=2$ for the overall reaction. This analysis

$$
K_{o b s(2+2)}=2 K_{\text {inter }} K_{\text {intra }}
$$

yields a $K_{\text {intra }}$ value of 45 . Prior work ${ }^{4 b, 21}$ has shown that flexible divalent compounds have an effective molarity (EM) of approximately $5 \mathrm{mM}$, referring to the ratio of $K_{\text {intra }} / 2 K_{\text {inter }}($ where $\sigma=1 / 2)$. If our 
$K_{\text {inter }}=5.5 \times 10^{3} \mathrm{M}^{-1}$, then an EM of $5 \mathrm{mM}$ would predict a $K_{\text {intra }}$ value of 55 . The similarity of this prediction to the actual value reported here (45) provides another example of the regular behavior of this system and thus its suitability as a model for multivalent interactions.

The detailed thermodynamic data provide an opportunity to dissect the formation divalent complexes by isolating the effects of linking two monovalent receptors $\left(\mathbf{1} \cdot \mathrm{Q} 8\right.$ vs. $\left.\mathbf{2} \cdot \mathrm{Q} 8_{2}\right)$ or two monovalent target peptides (4 vs. 5). The most direct comparison of thermodynamic data in these three complexes would require normalization to the same number of Q8•viologen•Trp interactions per complex. The modular design used in this system allows us to accomplish this estimation by doubling the values of $\Delta \mathrm{G}, \Delta \mathrm{H}$, and $-\mathrm{T} \Delta \mathrm{S}$ for the formation of $\mathbf{1} \cdot \mathrm{Q} 8 \bullet \mathbf{4}$ and $\mathbf{2} \cdot \mathrm{Q} 8_{2} \bullet \mathbf{4}_{2}$ because these are average values for each Q8•viologen $\bullet$ Trp interaction. ${ }^{22}$ From this comparison (Table 4), one can deduce that linking two monovalent receptors (i.e., $\mathbf{2} \cdot \mathrm{Q} 88_{2} \cdot \mathbf{4}_{2}$ vs. $\mathbf{1} \cdot \mathrm{Q} 8 \cdot \mathbf{4}$ ) results in a $3.2 \mathrm{kcal} / \mathrm{mol}$ increase in exothermicity with an almost exact $3.6 \mathrm{kcal} / \mathrm{mol}$ compensation in entropic energy. Linking two monovalent target peptides (i.e., $\mathbf{2} \cdot \mathrm{Q} 8_{2} \cdot \mathbf{5}$ vs. $\mathbf{2} \cdot \mathrm{Q} 8_{2} \cdot \mathbf{4}_{2}$ ) results in a $3.0 \mathrm{kcal} / \mathrm{mol}$ entropic penalty with a relatively small $0.8 \mathrm{kcal} / \mathrm{mol}$ loss in enthalpy. On the basis of this analysis, the suboptimal binding affinity observed in the formation of the $\mathbf{2} \cdot \mathrm{Q} 8_{2} \cdot \mathbf{5}$ complex derives primarily from an entropic penalty associated with the binding of divalent versus monovalent peptide. This analysis is consistent with a model in which significant conformational freedom is lost upon formation of the divalent complex.

Table 4. Dissection of the influence of linkage on divalent binding. ${ }^{\text {a }}$ 


\begin{tabular}{lcccc}
\hline Complex & multiplier & $\begin{array}{c}\Delta \mathrm{G} \\
(\mathrm{kcal} / \mathrm{mol})\end{array}$ & $\begin{array}{c}\Delta \mathrm{H} \\
(\mathrm{kcal} / \mathrm{mol})\end{array}$ & $\begin{array}{c}-\mathrm{T} \Delta \mathrm{S} \\
(\mathrm{kcal} / \mathrm{mol})\end{array}$ \\
\hline $\mathbf{1} \cdot \mathrm{Q} 8 \cdot \mathbf{4}$ & 2 & -12.0 & -21.8 & 9.8 \\
$\mathbf{2} \cdot \mathrm{Q} 8{ }_{2} \bullet \mathbf{4}_{2}$ & 2 & -11.6 & -25.0 & 13.4 \\
$\mathbf{2} \cdot \mathrm{Q} 8{ }_{2} \cdot \mathbf{5}$ & 1 & -7.8 & -24.2 & 16.4 \\
\hline
\end{tabular}

a These are values from Table 3 multiplied by the "multiplier" in the second column so that all values represent the binding of two Trp residues per complex.

Divalent Peptide Targets: A Model for Multivalent Binding. It is useful to compare our divalent system to an antibody molecule (e.g., IgG), in which the binding of the second site confers a modest 100-fold increase in affinity. ${ }^{23}$ The wide range of conformations observed for IgG molecules suggests a substantial conformational flexibility in the "hinge" that connects the two binding sites. ${ }^{24}$ The functional role of this flexibility remains a topic of current research, but the enormous size and structural complexity of antibody molecules substantially complicates these efforts. This example underscores the challenges involved in carrying out detailed studies of multivalent processes on proteins. As in many other successful areas of science, a good model system-one that embodies the essential characteristics of multivalency but is especially easy to study-is needed.

In addition to its importance as a submicromolar receptor for peptides in aqueous solution, the divalent system presented here has numerous features that make it well suited to serve as a model for studying multivalent complexation: 1) The monovalent complex is well understood. 2) The mode of divalent binding is simple, well defined, and similar to that observed for covalently linked multivalent receptors. That is, assembly of the divalent complexes proceeds noncooperatively, divalent complexes form in a discrete (non-oligomeric) fashion, and the observed intramolecular binding constant, $K_{\text {intra }}$, is similar to that of other flexible divalent complexes. 3) Synthesis is straightforward. Solid-phase synthetic methodology combined with noncovalent self-assembly enables the efficient synthesis of receptors and iterative modification of their linkers. 4) Analysis is straightforward. ITC combined with 
UV-visible spectroscopy allows for rapid determination of binding mode and quantitative measurement of the valency of the complex. Optical sensing of peptide targets is an additional benefit. 5) The system has several features that are representative of multivalent complexes in biological systems. The complexes form in neutral, buffered aqueous solution, the target compounds are peptides, and there is an observable increase in affinity due to multivalency. 6) The weaker than optimal increase in affinity is representative of antibodies and is desirable because it provides ample opportunity to uncover design principles for increasing the binding affinity through structure-activity studies.

Trivalent Peptide Target. Given the well-defined and predictable nature of the divalent complexes described above, we asked what would happen if the valency were extended to three. Based on the lack of distance-dependence observed in the divalent system, scaffold compound $\mathbf{3}$ and target peptide $\mathbf{6}$ were designed with only four intervening Gly residues between binding sites. The charge-transfer absorptivity of the trivalent complex, $\mathbf{3} \cdot \mathrm{Q} 8_{3} \cdot \mathbf{6}$, is three times that observed for the monovalent complexes, 1•Q8•4 (Figure 4). As discussed in detail for the divalent system above, this result demonstrates that essentially all of the available tryptophan residues are bound simultaneously, but it does not in itself allow for the unambiguous determination of binding mode. In the divalent complex, the two binding sites per molecule allow for only two possible binding modes: discrete macocycles and daisy-chain-like oligomers. In the trivalent system, the three binding sites per molecule enable more possible configurations, but the observed condition that all sites are bound simultaneously suggests that the only probable binding modes are discrete complexes and linear oligomers.

The ITC data for the trivalent complex shows a single transition centered at a $1: 1\left(\mathbf{6}: \mathbf{3} \cdot{ }^{\mathrm{Q}} 8_{3}\right)$ ratio (see Supporting Information, Figure S21). In contrast to the divalent system, however, the isotherm for the trivalent complex shows some asymmetry, with a steeper decrease in the magnitude of enthalpy in the first $2 / 3$ of the injections. ${ }^{16}$ This region fits well to a one-set-of-sites model, but the more shallow curvature of the remaining $1 / 3$ of the data points suggests an additional binding mode, the 
nature of which is unclear at this time. This result is not dramatic, but it is real, and it precludes the definitive assignment of this complex as discrete versus oligomeric. Given that (i) there is a clear midpoint at a 1:1 ratio, (ii) the first $\sim 2 / 3$ of the data points, including the early baseline and most of the transition region, is well defined by the data, and (iii) the end of the titration is defined by the heat of dilution, we estimated thermodynamic constants by fitting the first $2 / 3$ of the titration data to a one-setof-sites model. It should be noted that the UV-visible spectroscopy data in Figure 4 were acquired at the equivalence point, and thus are within the region defined by this analysis. Mass spectral data also verify the presence of the $\mathbf{3} \cdot \mathrm{Q} 8_{3} \cdot \mathbf{6}$ complex.

Although the binding mode is not definitive, the data provide a look at the properties of what is likely a discrete trivalent complex. With these qualifications in mind, we observe an increase in $\mathrm{K}_{\mathrm{a}}$ of $\sim 280$-fold due to multivalency, which is an enhancement of $\sim 10$-fold for the addition of a third binding site. This increase results from an approximate tripling of the favorable binding enthalpy and a more than tripling of the unfavorable binding entropy. The additive enthalpy is very similar to that observed for the divalent complexes; this similarity supports an assignment of a discrete trivalent complex.

As described above for the divalent complex, the observed binding constant for the formation of $\mathbf{3} \cdot \mathrm{Q} 8{ }_{3} \cdot \mathbf{6}, K_{o b s(3+3)}$, can be evaluated on the basis of the constituent inter- and intramolecular binding constants, $K_{\text {inter }}$ and $K_{\text {intra }}$. Using the approach detailed above for the divalent complexes, ${ }^{3 f}$ we derive a $K_{\text {inter }}$ value of $1.1 \times 10^{4} \mathrm{M}^{-1}$ and a $K_{\text {intra }}$ value of 15 . The $K_{\text {intra }}$ value is therefore approximately 3 -fold smaller than that of the divalent complex. Based on the argument that only $K$ values of the same dimensionality can be directly compared to assess cooperativity, ${ }^{3 \mathrm{f}}$ we conclude that the trivalent system shows a small degree of negative cooperativity as compared to the divalent complex.

Also as described for the divalent complex, the thermodynamic data for $\mathbf{3} \bullet \mathrm{Q} 83^{\bullet} \mathbf{6}$ can be dissected to assess the relative effects of linking three monovalent scaffolds (i.e., $1 \cdot Q 8 \bullet 4$ vs. $3 \cdot Q 88_{3} \mathbf{4}_{3}$ ) or three monovalent targets (i.e., $\mathbf{3} \cdot \mathrm{Q} 8_{3} \cdot \mathbf{4}_{3}$ vs. $\left.\mathbf{3} \cdot \mathrm{Q}_{3} \cdot \mathbf{6}\right)$. In order to normalize to the same number of binding events per complex, however, the thermodynamic state functions for $\mathbf{1} \bullet \mathrm{Q} 8 \bullet \mathbf{4}$ and $\mathbf{3} \bullet \mathrm{Q} 8_{3} \bullet \mathbf{4}_{3}$ must be 
multiplied by a factor of 3 . The resulting values (Table 5) show that linkage of three monovalent scaffolds leads to a $3.9 \mathrm{kcal} / \mathrm{mol}$ increase in favorable enthalpy with a compensating $4.5 \mathrm{kcal} / \mathrm{mol}$ increase in unfavorable entropy. Linkage of three monovalent target peptides provides an additional 2.8 $\mathrm{kcal} / \mathrm{mol}$ in favorable enthalpy but with a massive $11 \mathrm{kcal} / \mathrm{mol}$ loss in entropic energy. This trend is very similar to that observed for the divalent complex (as in Table 5); this similarity further supports an assignment of a discrete trivalent complex. The increasing loss in entropy in this system versus the divalent complexes is likely due to a decreasing probability of adopting a conformation in which all three sites are simultaneously bound without enthalpic penalty due to steric strain. If this trend is linearly extrapolated to complexes of higher valency, we would predict that starting with a heptavalent complex, the influence of multivalency would actually reduce the overall binding affinity.

Multivalent binding is often thought to be an entropically favorable process due to the reduced entropic penalty of translational and rotational freedom upon binding of two n-valent compounds as compared to the binding of $\mathrm{n}$ pairs monovalent analogues. ${ }^{1 \mathrm{a}}$ The contribution of this entropic advantage to the free energy of binding has been approximated at $\sim 5 \mathrm{kcal} / \mathrm{mol}$ per increase in the reaction order. $^{3 a, 25}$ Using this approximation, the entropic contribution to the free energy of binding of a divalent complex should be twice that of a monovalent complex less $5 \mathrm{kcal} / \mathrm{mol}$; we observe an additional 8-12 $\mathrm{kcal} / \mathrm{mol}$ entropic penalty beyond this approximation. Similarly, the entropic contribution to the free energy of binding of a trivalent complex should be three times that of a monovalent complex less 10 $\mathrm{kcal} / \mathrm{mol}$; we observe an additional $21-26 \mathrm{kcal} / \mathrm{mol}$ entropic penalty beyond this approximation. These results are in stark contrast to the expected entropic advantage of multivalency. The nature of this effect remains unclear. 
Table 5. Dissection of the influence of linkage on trivalent binding. ${ }^{\mathrm{a}}$

\begin{tabular}{lcccc}
\hline Complex & multiplier & $\begin{array}{c}\Delta \mathrm{G} \\
(\mathrm{kcal} / \mathrm{mol})\end{array}$ & $\begin{array}{c}\Delta \mathrm{H} \\
(\mathrm{kcal} / \mathrm{mol})\end{array}$ & $\begin{array}{c}-\mathrm{T} \Delta \mathrm{S} \\
(\mathrm{kcal} / \mathrm{mol})\end{array}$ \\
\hline $\mathbf{1 \cdot Q 8 \bullet 4}$ & 3 & -18.0 & -32.7 & 14.7 \\
$\mathbf{3} \cdot \mathrm{Q} 8 \mathbf{3}^{\circ} \mathbf{4}_{3}$ & 3 & -17.4 & -36.6 & 19.2 \\
$\mathbf{3} \cdot \mathrm{Q} 8 \mathbf{3}^{\bullet} \mathbf{6}$ & 1 & -9.2 & -39.4 & 30.2
\end{tabular}

a These are values from Tables $2(\mathbf{1} \cdot \mathrm{Q} 8 \cdot 4)$ and $3\left(3 \cdot \mathrm{Q} 83^{\bullet} 4_{3}\right.$ and $\left.3 \cdot \mathrm{Q} 83^{\bullet} 6\right)$ multiplied by the "multiplier" in the second column so that all values represent the binding of three Trp residues per complex.

\section{Conclusion}

This paper demonstrates a novel biomimetic approach to the construction of well-defined multivalent receptors via molecular self-assembly. We present a new class of synthetic receptors that assemble spontaneously from a modular scaffold presenting 1-3 viologen groups and an equivalent number of Q8 molecules. This noncovalent synthetic approach provides unparalleled economy for the purpose of iterative design and synthesis of multivalent receptors. We show that preassembled receptors bind to peptides containing multiple Trp residues in a multivalent fashion with affinity gains of 31-280-fold due to multivalency. The built-in optical sensor for tryptophan enables rapid and direct determination of the extent of valency using UV-visible spectroscopy, thus overcoming a common pitfall in the analysis of multivalent complexes. This technique, in combination with calorimetry and careful modular design of the scaffolds and targets, allows for convenient determination of the binding mode and comprehensive analysis of the binding thermodynamics. In addition to these advantages in synthesis and analysis, this system has several characteristics that make it remarkably well suited as a model for multivalent complexes: 1) It works in water. 2) The monovalent complex is well 
characterized. 3) Receptor assembly is noncooperative, and binding is additive; these features hugely simplify the equilibrium analysis. This system should facilitate iterative studies of structure-activity relationships in multivalent complexes, such as the effects of conformational entropy, ligand geometry, and higher valency. These studies are currently underway and will be reported in due course.

Acknowledgement. We thank Mr. Ray Skunda for preliminary contributions. This work was supported by grants from the Welch Foundation (W-1640), Research Corporation (CC6517), and the National Science Foundation (CHE-0748483). We gratefully acknowledge the donors of the American Chemical Society Petroleum Research Fund (PRF\#42220-GB4) for a startup grant that seeded the early stages of this project. Summer research fellowships to A. A. K. were provided by Prof. John A. Burke and by the Howard Hughes Medical Institute. We thank the W. M. Keck Foundation for generous support to Trinity University that made available the mass spectrometer and titration calorimeter used in this study as well as a summer stipend to B. T. H.

Supporting Information Available: Experimental details; ${ }^{1} \mathrm{H}$ NMR and mass spectrometry characterization of new compounds; ITC data and mass spectra of all complexes; UV-visible spectra of charge-transfer complexes.

\section{References}

(1) a) Mammen, M.; Choi, S.-K.; Whitesides, G. M. Angew. Chem. Int. Ed. 1998, 37, 2754-2797. b) Mulder, A.; Huskens, J.; Reinhoudt, D. N. Org. Biomol. Chem. 2004, 2, 3409-3424. c) Badjic, J. D.; Nelson, A.; Cantrill, S. J.; Turnbull, W. B.; Stoddart, J. F. Acc. Chem. Res. 2005, 38, 723-732. d) Kiessling, L. L.; Gestwicki, J. E.; Strong, L. E. Angew. Chem. Int. Ed. 2006, 45, 2348-2368.

(2) a) Roy, R. Curr. Opin. Struct. Biol. 1996, 6, 692-702. b) Choi, S.-K. Synthetic Multivalent 
Molecules: Concepts and Biomedical Applications; John Wiley \& Sons: Hoboken, NJ, 2004. c) Lee, Y.; Sampson, N. S. Curr. Opin. Struct. Biol. 2006, 16, 544-550.

(3) a) Lundquist, J. J.; Toone, E. J. Chem. Rev. 2002, 102, 555-578. b) Gestwicki, J. E.; Cairo, C. W.; Strong, L. E.; Oetjen, K. A.; Kiessling, L. L. J. Am. Chem. Soc. 2002, 124, 14922-14933. c) Brewer, C. F.; Miceli, M. C.; Baum, L. G. Curr. Opin. Struct. Biol. 2002, 12, 616-623. d) Christensen, T.; Gooden, D. M.; Kung, J. E.; Toone, E. J. J. Am. Chem. Soc. 2003, 125, 7357-7366. e) Kitov, P. I.; Bundle, D. R. J. Am. Chem. Soc. 2003, 2003, 16271-16284. f) Ercolani, G. J. Am. Chem. Soc. 2003, $125,16097-16103$.

(4) a) Breslow, R.; Zhang, B. J. Am. Chem. Soc. 1996, 118, 8495-8496. b) Rao, J.; Lahiri, J.; Weis, R. M.; Whitesides, G. M. J. Am. Chem. Soc. 2000, 122, 2698-2710. c) Fulton, D. A.; Cantrill, S. J.; Stoddart, J. F. J. Org. Chem. 2002, 67, 7968-7981. d) Liu, Y.; Chen, Y. Acc. Chem. Res. 2006, 39, 681691.

(5) Connors, K. A. Binding Constants: The Measurement of Molecular Complex Stability; Wiley \& Sons, Inc.: New York, 1987.

(6) a) Mock, W. L.; Shih, N.-Y. J. Org. Chem. 1983, 48, 3618-3619. b) Kim, J.; Jung, I.-S.; Kim, S.Y.; Lee, E.; Kang, J.-K.; Sakamoto, S.; Yamaguchi, K.; Kim, K. J. Am. Chem. Soc. 2000, 122, 540-541. c) Day, A. I.; Arnold, A. P.; Blanch, R. J.; Snushall, B. J. Org. Chem. 2001, 66, 8094-8100. d) Lee, J. W.; Samal, S.; Selvapalam, N.; Kim, H.-J.; Kim, K. Acc. Chem. Res. 2003, 36, 621. e) Lagona, L.; Mukhopadhyay, P.; Chakrabarti, S.; Isaacs, L. Angew. Chem. Int. Ed. 2005, 44, 4844-4870.

(7) a) Jeon, W. S.; Moon, K.; Park, S. H.; Chun, H.; Ko, Y. H.; Lee, J. Y.; Lee, E. S.; Samal, S.; Selvapalam, N.; Rekharsky, M. V.; Sindelar, V.; Sobransingh, D.; Inoue, Y.; Kaifer, A. E.; Kim, K. J. Am. Chem. Soc. 2005, 127, 12984-12989. b) Liu, S.; Ruspic, C.; Mukhopadhyay, P.; Chakrabarti, S.; Zavalij, P. Y.; Isaacs, L. J. Am. Chem. Soc. 2005, 127, 15959-15967. c) Hwang, I.; Baek, K.; Jung, M.; 
Kim, Y.; Park, K. M.; Lee, D.-W.; Selvapalam, N.; Kim, K. J. Am. Chem. Soc. 2007, 129, 4170-4171.

d) Rekharsky, M. V.; Mori, T.; Yang, C.; Young, H. K.; Selvapalam, N.; Kim, H.; Sobransingh, D.; Kaifer, A. E.; Liu, S.; Isaacs, L.; Chen, W.; Moghaddam, S.; Gilson, M. K.; Kim, O.; Inoue, Y. Proc. Natl. Acad. Sci. USA 2007, 104, 20737-20742. e) Koner, A. L.; Nau, W. M. Supramol. Chem. 2007, 19, 55-66.

(8) a) Jeon, W. S.; Kim, H.; Lee, C.; Kim, K. Chem. Commun. 2002, 1828-1829. b) o, Y. H.; Kim, E.; Hwang, I.; Kim, K. Chem. Comm. 2007, 1305-1315.

(9) a) Liu, S. M.; Zavalij, P. Y.; Isaacs, L. J. Am. Chem. Soc. 2005, 127, 16798-16799. b) Liu, S.; Shukla, A. D.; Gadde, S.; Wagner, B. D.; Kaifer, A. E.; Isaacs, L. Angew. Chem. Int. Ed. 2008, 47, 2657-2660.

(10) Huang, W. H.; Liu, S. M.; Zavalij, P. Y.; Isaacs, L. J. Am. Chem. Soc. 2006, 128, 14744-14745.

(11) Bush, M. E.; Bouley, N. D.; Urbach, A. R. J. Am. Chem. Soc. 2005, 127, 14511-14517.

(12) a) US Patent; Kim, K.; Kim, J.; Jung, I.-S.; Kim, S.-Y.; Lee, E.; Kang, J.-K.; Pohang University of Science and Technology Foundation: 2000. b) Kim, H.-J.; Heo, J.; Jeon, W. S.; Lee, E.; Kim, J.; Sakamoto, S.; Yamaguchi, K.; Kim, K. Angew. Chem. Int. Ed. 2001, 40, 1526-1529. c) Rajgariah, P.; Urbach, A. R. J. Incl. Phenom. Macrocyc. Chem. 2008, 62, 251-254.

(13) a) Breslow, R.; Yang, Z.; Ching, R.; Trojandt, G.; Odobel, F. J. Am. Chem. Soc. 1998, 120, 3536-3537. b) Fessman, T.; Kilburn, J. D. Angew. Chem. Int. Ed. 1999, 38, 1993-1996. c) Sirish, M.; Schneider, H.-J. Chem. Comm. 1999, 907-908. d) Wennemers, H.; Conza, M.; Nold, M.; Krattiger, P. Chem. Eur. J. 2001, 7, 3342-3347. e) Nelson, A.; Belitsky, J. M.; Vidal, S.; Joiner, C. S.; Baum, L. G.; Stoddart, J. F. J. Am. Chem. Soc. 2004, 126, 11914-11922. f) Mandl, C. P.; Konig, B. J. Org. Chem. 2005, 70, 670-674. g) Tashiro, S.; Tominaga, M.; Kawano, M.; Therrien, B.; Ozeki, T.; Fujita, M. J. Am. Chem. Soc. 2005, 127, 4546-4547. 
(14) (footnote) All references to compounds 1, 2, 4, and 5 that are not designated as $\mathbf{a}$ or $\mathbf{b}$ refer to both compounds. For example, scaffolds $\mathbf{1}$ refers to both $\mathbf{1 a}$ and $\mathbf{1 b .}$

(15) (footnote) All data fit well to the "one set of sites" model in Origin 7.0 software, which assumes all sites are equivalent and noninteracting. Accordingly, in cases where the molar ratio of titrant to sample is greater than or equal to one, the thermodynamic values describe the binding per mole of sample. In cases where this ratio is less than one, the values describe the binding per mole of titrant; this changeover is accomplished in the software by redefining the parameters of the isotherm equation such that the compound with multiple binding sites is the sample. All such assignments were consistent with the compounds being tested, on the basis of the observed stoichiometery (from ITC) and of confirmation by electrospray mass spectrometry.

(16) (footnote) As in the assembly of receptors described above, the ITC data for the formation of $\mathbf{1} \cdot \mathrm{Q} 8 \cdot \mathbf{4}, \mathbf{2} \cdot \mathrm{Q}_{2} \cdot \mathbf{4}_{2}$, and $\mathbf{2} \cdot \mathrm{Q} 8_{2} \cdot \mathbf{5}$ fit well to the one-set-of-sites model in Origin software, and thermodynamic constants are per mole of titrant (i.e., target peptide). The ITC data for the formation of $\mathbf{3} \cdot \mathrm{Q} 8{ }_{3} \cdot \mathbf{6}$, however, is not as simple to interpret (see supporting information, Figure $\mathrm{S} 21$ ): the isotherm shows some asymmetry, with a steeper decrease in molar enthalpy before the equivalence point than after. The first $\sim 2 / 3$ of the titration, up to a stoichiometry of $\sim 1.5: 1\left(6: 3 \cdot Q 8_{3}\right)$, fit well to a one-set-ofsites model, showing a steeper transition before the equivalence point than after; the last $\sim 1 / 3$ of the data points show a more shallow transition, however, which is indicative of a second type of binding event at higher stoichiometric ratios. The thermodynamic constants reported in Table 2 for the formation of $3 \cdot \mathrm{Q}_{3} \bullet \mathbf{6}$ derive from a fitting of the first $\sim 2 / 3$ of the data points to a one-set-of-sites binding model. We note explicitly that this analysis of the data is not entirely accurate because the entire isotherm is not well defined. Further analysis is provided in the Discussion section.

(17) (footnote) In calculating the molar absorptivities, we used the equilibrium concentration of complex, which was calculated using the equilibrium constants reported in Table 2 and the experimental 
concentrations. For example, the equilibrium concentration differed from the initial concentration by $22.0 \%$ for the $\mathbf{1} \mathbf{a} \cdot \mathrm{Q} 8 \cdot \mathbf{4} \mathbf{a}$ complex, $8.7 \%$ for the $\mathbf{2} \mathbf{a} \cdot \mathrm{Q} 8{ }_{2} \cdot \mathbf{5 a}$ complex, and $2.2 \%$ for the $\mathbf{3} \cdot \mathrm{Q} 8{ }_{3} \cdot \mathbf{6}$ complex.

(18) Moon, K.; Kaifer, A. E. Organic Letters 2004, 6, 185-188.

(19) Heitmann, L. M.; Taylor, A. B.; Hart, P. J.; Urbach, A. R. J. Am. Chem. Soc. 2006, 128, 1257412581.

(20) (footnote) The symmetry factor $(\sigma)$ is assigned based on a consideration of the symmetries of reactants and products (we explicitly ignore the directionality of the peptide chains and we assume that viologen-Q8 complexes are fixed under the experimental conditions) such that a 2 -fold rotational symmetry is assigned to compound $\mathbf{2}$ and to complex $\mathbf{1} \cdot \mathrm{Q} 8$, and $\sigma_{\text {reaction }}=\Sigma \sigma_{\text {reactants }}-\Sigma \sigma_{\text {products }}=4$.

(21) Gargano, J. M.; Ngo, T.; Kim, J. Y.; Acheson, D. W. K.; Lees, W. J. J. Am. Chem. Soc. 2001, $123,12909-12910$.

(22) (footnote) This treatment would predict approximately twice the energy of binding for a divalent (i.e., $\left.\mathbf{2} \cdot \mathrm{Q} 88_{2} \cdot \mathbf{5}\right)$ versus monovalent (i.e., $\left.\mathbf{1} \cdot \mathrm{Q} 8 \cdot \mathbf{4}\right)$ complex. We note explicitly that this estimation neglects the advantage of the translational and rotational entropy inherent to multivalent systems ${ }^{1 \mathrm{a}}$ but that this advantage is rarely $\operatorname{seen}^{1 \mathrm{~b}}$ and is expected to be small $(\sim 0.5 \mathrm{kcal} / \mathrm{mol})$ relative to the effects discussed here.

(23) a) Hornick, C. L.; Karush, F. Immunochem. 1972, 9, 325-340. b) Karulin, A. Y.; Dzantiev, B. B. Mol. Immunol. 1990, 27, 965-971.

(24) a) Davies, D. R.; Chacko, S. Acc. Chem. Res. 1993, 26, 421-427. b) Saphire, E. O.; Stanfield, R. L.; Crispin, M. D. M.; Parren, P. W. H. I.; Rudd, P. M.; Dwek, R. A.; Burton, D. R.; Wilson, I. A. J. Mol. Biol. 2002, 319, 9-18.

(25) Jencks, W. P.; Catalysis in Chemistry and Enzymology; Dover Publications, Inc.; New York; 
1987.

\section{Table of Contents Graphic:}

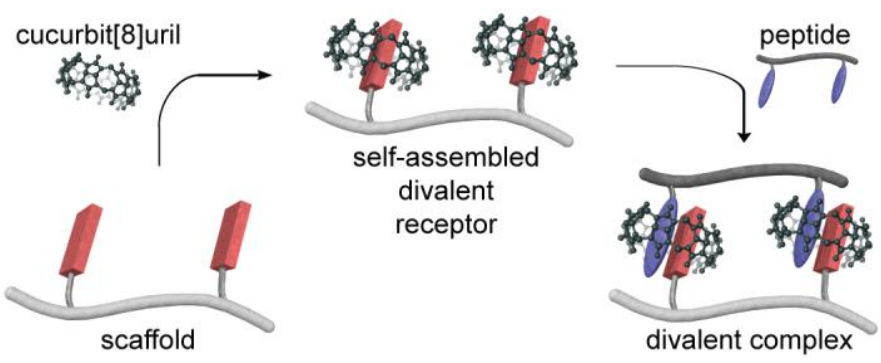

